\title{
PENGARUH INSENTIF TERHADAP KINERJA KARYAWAN DENGAN MOTIVASI SEBAGAI VARIABEL MODERASI (Studi pada Agen PT. Jiwasraya Kantor Cabang Malang Kota)
}

\author{
Galaxy Mustofa \\ Department of Management FEB UMM \\ E-mail: galaxymustofa@gmail.com
}

\begin{abstract}
The purpose of the study describes the incentive, motivation and performance of employees at PT. Jiwasraya Malang Branch Office City, analyzed the effect of incentives on employee performance with motivation as a moderating variable. Sample research is a marketing agent associate amounting. Sampling using Total Sampling technique.. Simple linear regression analysis to determine the effect between incentive variable and employee performance. Moderate analysis to find out the moderation relationship between the influences of incentives on employee performance. The results showed that employee performance in very low category, incentives enter in good category and motivation included in low category. Incentives affect employee performance. Motivation variable moderate the influence of incentive to employee performance. Moderate variables increase the percentage of influence of employee incentives and performance which means motivation strengthen the influence of incentives on employee performance.
\end{abstract}

Keywords: incentives, motivation, employee performance

\section{PENDAHULUAN}

Persaingan yang ketat didunia bisnis menyebabkan setiap perusahaan harus bisa beradaptasi menyesuaikan kondisi mereka dengan keadaan dan perubahan yang terjadi. Perusahaan harus tanggap menciptakan strategi yang mereka jalankan untuk memenangkan persaingan dan mempertahankan bisnisnya. Perusahaan harus terus meningkatkan keuntungan yang diperolehnya, salah satu faktor terpenting dalam mewujudkan ini adalah Sumber Daya Manusia (SDM).

Perusahaan dapat mencapai keberhasilan melalui kinerja SDM yang dimilikinya. Kinerja menurut
Mangkunegara (2010) adalah hasil kerja secara kualitas maupun kuantitas yang dicapai oleh seorang karyawan dalam melaksanakan tugasnya sesuai tanggungjawab pekerjaannya.

Kinerja karyawan dipengaruhi oleh beberapa faktor yaitu kepuasan kerja, tingkat stres, kondisi fisik, pekerjaan, sistem kompensasi dan aspek-aspek ekonomi (Susilo 2002). Dapat dicermati salah satu faktor terpenting dalam upaya peningkatan kinerja adalah sistem kompensasi. Sistem kompensasi didalamnya menyangkut insentif (Husein 2007).

Insentif adalah pemberian upah atau gaji yang berbeda bukan didasarkan pada jabatannya namun 
karena perbedaan prestasi kerja (Samsudin, 2006). Tujuan insentif untuk meningkatkan motivasi dalam upaya mencapai tujuan perusahaan (Handoko, 2010). Motivasi berkaitan dengan bagaimana mendorong kerja bawahan agar mau memberikan semua kemampuannya untu mewujudkan tujuan perusahaan (Hasibuan, 2010).

Berbagai hasil penelitian telah dilakukan yaitu Firman Alamsyah (2013) menunjukkan bahwa insentif berpengaruh signifikan terhadap kinerja karyawan adalah benar dan dapat diterima. Nuraini Firmandari (2014) membuktikan kompensasi dan motivasi berpengaruh signifikan terhadap kinerja, motivasi memoderasi hubungan antara kompensasi dan kinerja.

PT Jiwasraya (Persero) adalah perusahaan yang fokus bergerak dalam bisnis jasa asuransi. SDM perusahaan Jiwasraya ada dua macam yaitu karyawan tetap dan agen. Agen merupakan ujung tombak pemasaran produk asuransi Jiwasraya. Maju mundurnya perusahaan ditentukan oleh kinerja agen ini.

Kinerja agen PT. Jiwasraya Kantor Cabang Malang Kota dalam beberapa tahun terakhir dianggap belum memenuhi target perusahaan. Tepatnya dalam tahun 2014-2016. Hasil ini dapat dilihat dalam tabel kinerja berikut ini :

Tabel 1. Data Kinerja Agen Marketing Associated 2014-2016 (dalam Rp)

\begin{tabular}{cccccccc}
\hline \multirow{2}{*}{ Tahun } & \multicolumn{2}{c}{ Target 1 Tahun } & \multicolumn{2}{c}{ Realisasi } & \multicolumn{2}{c}{ Pencapaian $(\%)$} & \multirow{2}{*}{ Ket. } \\
\cline { 2 - 6 } & Premi & Polis & Premi & Polis & Premi & Polis & \\
\hline 2014 & 120.000 .000 & 12 & 49.157 .000 & 6 & 45 & 46,1 & Tidak Tercapai \\
2015 & 120.000 .000 & 12 & 35.671 .000 & 4 & 30 & 30,7 & Tidak Tercapai \\
2016 & 120.000 .000 & 12 & 24.249 .000 & 3 & 25 & 23,2 & Tidak Tercapai \\
\hline
\end{tabular}

Data tabel diatas mengambarkan rata-rata kinerja agen Marketing Associated rendah karena tingkat pencapaian agen dalam 3 tahun tersebut tidak mampu mencapai target premi dan polis perusahaan bahkan pencapaian premi dan polis semakin menurun.

Jiwasraya menerapkan strategi memberikan insentif dalam bentuk komisi, persistensi polis dan bonus wisata kepada agen untuk mendorong agen agar lebih giat mencari nasabah.

Bonus di PT. Jiwasraya adalah wisata ke berbagai tempat menarik namun bonus ini jarang diraih oleh agen Marketing Assosiated PT Jiwasraya Cabang Malang Kota.

Data tabel dibawah dapat menunjukkan bahwa hanya 2 dari 47 agen Marketing Associated yang mendapatkan bonus wisata tujuan domestik (Batam-Singapura) bonus wisata tujuan lain tidak ada yang tercapai. Cara mendapatkan poin dalam bonus wisata PT. Jiwasraya adalah dengan jumlah pencapaian premi. Pencapaian dalam jenis premi sekaligus dibagi Rp5.000.000 dan jenis premi berkala dibagi Rp1.000.000. Hasil pembagian tersebut akan menunjukan jumlah poin yang didapat. 
Tabel 2. Data Bonus Wisata Agen Marketing Associated Jiwasraya Cabang Malang Kota Tahun 2016

\begin{tabular}{clccc}
\hline \multirow{2}{*}{ No } & \multicolumn{1}{c}{ Keterangan } & \multicolumn{2}{c}{ Realisasi } \\
\cline { 2 - 5 } & \multicolumn{1}{c}{ Jenis Bonus Wisata } & Target & Pencapaian & Keterangan \\
\hline 1 & Tujuan Eropa (Amsterdam-Paris) & 650 poin & 0 & Tidak Dapat \\
2 & Tujuan Holy Land (Kristiani) & 500 poin & 0 & Tidak Dapat \\
3 & Tujuan Umroh (Islam) & 350 poin & 0 & Tidak Dapat \\
4 & Tujuan Asia (Korea Selatan-Jeju) & 300 poin & 0 & Tidak Dapat \\
5 & Tujuan Domestik (Batam-Singapura) & 175 poin & 2 & Tidak Dapat \\
\hline
\end{tabular}

Tujuan penelitian adalah mendeskripsikan insentif, motivasi dan kinerja agen PT. Jiwasraya Cabang Malang Kota. Selain itu untuk menguji dan menganalisis pengaruh insentif terhadap kinerja dan menguji dan menganalisis peran motivasi dalam memoderasi pengaruh insentif terhadap kinerja agen PT. Jiwasraya Cabang Malang Kota.

\section{TINJAUAN PUSTAKA}

Mangkunegara (2009), kinerja adalah hasil kerja secara kualitas dan kuantitas yang dicapai oleh seorang pegawai dalam melaksanakan tugasnya sesuai dengan tanggung jawab yang diberikan kepadanya. Indikator untuk mengukur kinerja yaitu kualitas, kuantitas dan ketepatan waktu

Insentif adalah pemberian upah yang berbeda bukan didasarkan pada evaluasi jabatan namun karena perbedaan prestasi kerja (Samsudin 2006). Jenis-jenis insentif dapat dibagi menjadi dua yaitu insentif materiil dan non materiil (Sarwoto, 2006).

Motivasi menurut Harbani
(2010) adalah sesuatu yang
menimbulkan semangat atau
dorongan kgerja. Keterkaitan antara
kinerja, insentif dan motivasi
digambarkan berikut:

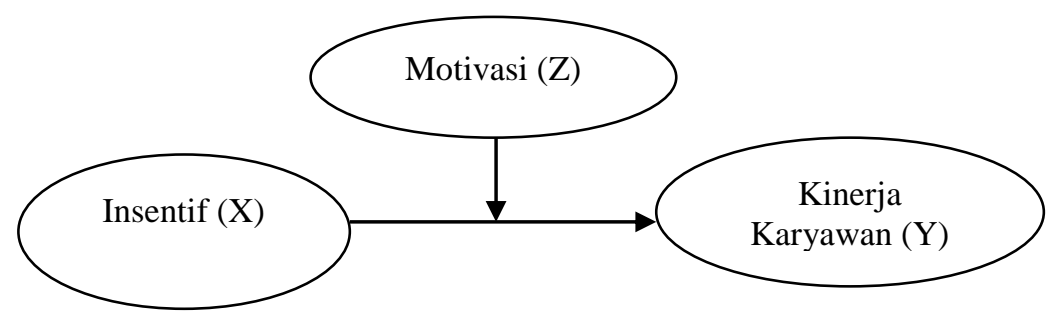

Gambar 1. Kerangka Pikir

Kerangka pikir ini menjelaskan insentif sebagai variabel independen dengan indikator yaitu insentif material (Sarwoto, 2000). Insentif tersebut berpengaruh langsung terhadap kinerja karyawan sebagai variabel dependen dengan indikator yaitu kuantitas kerja dan ketepatan waktu (Robbins, 2006).
Kerangka pikir ini juga menunjukkan motivasi sebagai variabel moderasi yang mempengaruhi hubungan antara insentif dengan kinerja karyawan dengan indikator Teori Aldefer dalam Munandar (2001) yaitu dorongan kebutuhan untuk eksis, dorongan kebutuhan untuk menjalin 
hubungan dan dorongan kebutuhan untuk berkembang.

Penelitian yang telah dilakukan oleh Firman alamsyah (2013) mendapatkan hasil bahwa insentif berpengaruh signifikan terhadap kinerja karyawan di Coal Mining Departement PT. Kalim Prima Coal adalah benar dan dapat diterima.

Penelitian Nuraini Firmandari (2014) tentang pengaruh kompensasi terhadap kinerja dengan motivasi kerja sebagai variable moderasi pada bank syariah mandiri kantor cabang Yogjakarta membuktikan pengaruh positif dan signifikan kompensas terhadap kinerja dan motivasi memoderasi hubungan antara kompensasi dengan kinerja.

Penelitian Hari Yogi, dkk (2015) pengaruh insentif terhadap motivasi dan kinerja karyawan hotel Pujon View Kabupaten Malang mendapatkan hasil insentif berpengaruh signifikan terhadap motivasi, insentif juga berpengaruh signifikan terhadap kinerja dan motivasi kerja berpengaruh positif terhadap kinerja.

\section{METODE PENELITIAN}

Penelitian ini merupakan penelitian eksplanatori dengan metode asosiatif. Populasi pada penelitian ini adalah semua agen dengan status agen marketing assiciated di PT. Jiwasraya Kantor Cabang Malang Kota yang berjumlah 47 agen. Teknik pengambilan sampel yang digunakan adalah total sampling yaitu semua anggota dalam populasi.

Sumber data yang digunakan adalah data primer, yaitu hasil kuesioner dan data sekunder, yaitu data literatur yang mendukung penelitian. Pengukuran item dalam angket menggunakan skala likert lima tingkat.

Pengujian instrumen dengan uji validitas dan uji realibilitas, sedangkan teknik analisis data yang digunakan yakni rentang skala dan Moderated Regression Analysis (MRA). Perhitungan rentang skala dengan sampel berjumlah 47 mendapatkan hasil rentang skala sebesar 38. Kriteria rentang skala akan ditampilkan Tabel 3:

Tabel 3. Rentang Skala

\begin{tabular}{cccc}
\hline Kriteria & Insentif & Motivasi & Kinerja \\
\hline $47-84$ & Sangat Buruk & Sangat Rendah & Sangat Rendah \\
$85-122$ & Buruk & Rendah & Rendah \\
$123-160$ & Cukup & Cukup & Cukup \\
$161-198$ & Baik & Tinggi & Tinggi \\
$199-235$ & Sangat Baik & Sangat Tinggi & Sangat Tinggi \\
\hline
\end{tabular}

\section{HASIL DAN PEMBAHASAN}

Uji validitas adalah langkah pengujian yang dilakukan terhadap isi instrument. Uji validitas digunakan untuk melihat valid tidaknya masing-masing instrumen. Responden penelitian ini berjumlah 47 orang sehingga nilai $r$ tabel sebesar 0,281 dengan taraf signifikan $0,05(5 \%)$. 
Tabel 4. Tabulasi Hasil Uji Validitas

\begin{tabular}{clcccc}
\hline Variabel & \multicolumn{1}{c}{ Sub variabel } & No item & r hitung & r tabel & Keterangan \\
\hline Insentif & Pemberian komisi & X1 & 0,843 & 0,281 & Valid \\
(X) & Pemberian bonus wisata & X2 & 0,805 & 0,281 & Valid \\
& Pemberian persistensi polis & X3 & 0,877 & 0,281 & Valid \\
Kinerja & Kuantitas & Y1 & 0,865 & 0,281 & Valid \\
$(Y)$ & Ketepatan waktu & Y2 & 0,762 & 0,281 & Valid \\
& Kebutuhan eksistensi & Y3 & 0,886 & 0,281 & Valid \\
Motivasi & Sub variable & Z2 & 0,721 & 0,281 & Valid \\
kerja & Kebutuhan menjalin & No item & r hitung & r tabel & Keterangan \\
Motivasi & Hubungan & Z4 & 0,767 & 0,281 & Valid \\
kerja & Kebutuhan berkembang & Z5 & 0,630 & 0,281 & Valid \\
& Z6 & 0,822 & 0,281 & Valid \\
\end{tabular}

Tabel 4. menunjukan masingmasing indikator penelitian ini yang meliputi variabel insentif, kinerja karyawan dan motivasi mempunyai nilai $r$ hitung lebih besar dari $r$ tabel. Hasil ini dapat menyimpulkan jika item dalam pertanyaan yang digunakan sudah valid atau layak digunakan sebagai pengumpul data.

Realibilitas adalah indeks yang menunjukkan sejauh mana alat ukur dapat dihandalkan. Dengan kriteria nilai dari koefisien reliabilitas Cronbach's alpha lebih dari sama dengan 0,6. Hasil uji reliabilitas ditunjukan Tabel 5 . berikut ini :
Tabel 5. Tabulasi Hasil Uji Realibilitas

\begin{tabular}{ccc}
\hline Variabel & $\begin{array}{c}\text { Alpha } \\
\text { Cronbach }\end{array}$ & Keterangan \\
\hline Insentif & 0,757 & Reliabel \\
Kinerja & 0,786 & Reliabel \\
Motivasi kerja & 0,847 & Reliabel \\
\hline
\end{tabular}

Tabel 5. Menunjukan nilai Cronbach's alpha tiap variabel lebih dari 60\%, sehingga instrumen penelitian ini handal karena dapat menghasilkan jawaban responden yang konsisten.

Pengukuran rentang skala insentif digunakan untuk melihat bagaimana peryataan insentif agen marketing assosiate PT. Jiwasraya.

Tabel 6. Rentang Skala Variabel Insentif (X)

\begin{tabular}{|c|c|c|c|c|c|c|c|c|}
\hline Item & SS & $\mathrm{S}$ & $\mathrm{RR}$ & $\mathrm{TS}$ & STS & Jumlah Responden & Rentang Skala & Ket \\
\hline $\mathrm{X} 1$ & 10 & 22 & 13 & 2 & 0 & 47 & 181 & Baik \\
\hline $\mathrm{X} 2$ & 0 & 0 & 37 & 10 & 0 & 47 & 131 & Cukup \\
\hline X3 & 9 & 25 & 12 & 1 & 0 & 47 & 183 & Baik \\
\hline \multicolumn{9}{|r|}{ Baik } \\
\hline
\end{tabular}

Tabel 6 merupakan hasil analisis rentang skala untuk variabel insentif yang mana menunjukkan bahwa insentif agen PT. Jiwasraya Cabang Malang Kota masuk dalam kategori baik.

Tabel 7. Rentang Skala Variabel Kinerja Karyawan (Y)

\begin{tabular}{|c|c|c|c|c|c|c|c|c|}
\hline Item & SS & $S$ & RR & $\mathrm{TS}$ & STS & Jumlah Responden & Rentang Skala & Ket \\
\hline Y1 & 0 & 0 & 0 & 16 & 31 & 47 & 67 & Sangat rendah \\
\hline Y2 & 0 & 0 & 0 & 8 & 39 & 47 & 55 & Sangat rendah \\
\hline Y3 & 0 & 1 & 22 & 24 & 0 & 47 & 118 & Rendah \\
\hline \multicolumn{7}{|c|}{ Rata-rata } & 80 & Sangat Rendah \\
\hline
\end{tabular}


Tabel 7. merupakan hasil analisis rentang skala untuk variabel kinerja karyawan. Dapat disimpulkan bahwa kinerja agen PT. Jiwasraya Cabang Malang Kota masuk dalam kategori sangat rendah.

Tabel 8. Rentang Skala Variabel Motivasi (Z)

\begin{tabular}{ccccccccc}
\hline Item & SS & S & RR & TS & STS & Jumlah Responden & Rentang Skala & Ket \\
\hline Z1 & 0 & 0 & 0 & 12 & 35 & 47 & 59 & Sangat Rendah \\
Z2 & 0 & 0 & 1 & 23 & 23 & 47 & 72 & Sangat Rendah \\
Z3 & 0 & 0 & 0 & 28 & 19 & 47 & 75 & Sangat Rendah \\
Z4 & 0 & 0 & 5 & 36 & 6 & 47 & 93 & Rendah \\
Z5 & 0 & 0 & 27 & 20 & 0 & 47 & 121 & Rendah \\
Z6 & 0 & 0 & 10 & 31 & 6 & 47 & 98 & Rendah \\
\hline \multicolumn{8}{c}{ Rata-rata }
\end{tabular}

Berdasarkan hasil analisis rentang skala dari nilai rata-rata variabel motivasi dapat disimpulkan motivasi agen PT. Jiwasraya Cabang Malang Kota masuk dalam kategori rendah. Analisis ini bertujuan untuk menguji dan menganalisis pengaruh insentif terhadap kinerja karyawan yang dimoderasi oleh motivasi. Adapun hasil pengujiannya yaitu:

Tabel 9. Hasil Moderated Regression Analysis (MRA)

\begin{tabular}{lccc}
\hline & Koefisien & $\mathrm{t}_{\text {hitung }}$ & Signifikansi \\
\hline Konstanta & 10,247 & & \\
Insentif (X) & $-0,736$ & $-1,024$ & 0,012 \\
Motivasi (Z) & $-0,880$ & $-1,709$ & 0,004 \\
Moderasi X*Z & 0,103 & 3,313 & 0,000 \\
$\mathrm{R}$ & 0,841 & & \\
$\mathrm{R}^{2}$ & 0,707 & & \\
F Statistik & 34,539 & & 0,000 \\
\hline
\end{tabular}

Berdasarkan hasil penelitian pada Tabel 9 maka didapatkan persamaan regresi sebagai berikut, $\mathrm{Y}=10,247$ 0,736X-0,880Z+0,103 XZ + e

Persamaan ini menunjukkan halhal sebagai berikut: (a) $=10,247$ merupakan nilai konstanta, yaitu estimasi dari kinerja agen PT. Jiwasraya Kantor Cabang Malang Kota apabila variabel insentif, motivasi dan interkasi insentif dengan motivasi diasumsikan bernilai $0 .\left(b_{1} \mathrm{X}\right)=-0,736$ adalah koefisien arah variabel insentif.

Hasil analisis menunjukkan nilai koefisien regresi sebesar -0,736 dengan tanda negatif. Artinya apabila insentif naik satu satuan, maka kinerja karyawan akan turun sebesar
$-0,736$ jika variabel $\mathrm{Z}$ dan $\mathrm{XZ}$ dianggap mempunyai nilai sama dengan nol. Hasil ini mengambarkan jika insentif yang berkaitan dengan persistensi polis semakin naik maka akan menurunkan kinerja agen. Hal ini disebabkan nilai imbalan dari persistensi polis yang kecil sehingga agen kurang tertarik dan lebih mengharapkan pada kenaikan jenis insentif yang lain. $\left(b_{2} X\right)=-0,880$ adalah koefisien regresi motivasi ( $\mathrm{Z}$ ) terhadap kinerja karyawan (Y). Hasil analisis menunjukkan bahwa apabila motivasi naik satu satuan, maka kinerja karyawan akan turun sebesar $-0,880$ jika variabel $\mathrm{X}$ dan $\mathrm{XZ}$ dianggap konstan. Hasil ini mengambarkan jika motivasi agen 
yang berkaitan dengan kesempatan mengembangkan karir semakin tinggi maka akan menurunkan kinerja agen. Hal ini disebabkan pekerjaan sebagai agen oleh responden dianggap bukan pekerjaan utama sehingga mereka kurang peduli dengan karirnya. Agen lebih mengiginkan faktor-faktor motivasi dalam bentuk yang lain. $\left(b X^{*} \mathrm{Z}\right)=$ 0,103 merupakan slope atau variabel moderasi $\left(\mathrm{X}^{*} \mathrm{Z}\right)$. Hasil tersebut menunjukkan bahwa penambahan satu satuan interaksi antara insentif dan motivasi mengakibatkan terjadinya peningkatan kinerja karyawan sebesar 0,103 jika variabel $\mathrm{X}$ dan $\mathrm{Z}$ konstan. Hasil tersebut berarti jika insentif semakin baik dengan disertai motivasi yang semakin tinggi, maka kinerja karyawan juga akan semakin tinggi.
Berdasarkan analisis $M R A$ pada Tabel 9 diperoleh hasil $\mathrm{R}^{2}$ sebesar 0,707. Hal ini menunjukan keragaman variabel kinerja dapat dijelaskan oleh variabel insentif dengan moderasi motivasi sebesar 0,707 atau kontribusi motivasi dalam memoderasi pengaruh insentif terhadap kinerja karyawan sebesar $70,7 \%$, sedangkan sisanya sebesar $29,3 \%$ merupakan variabel lain yang tidak dibahas dalam penelitian ini.

Hipotesis 1 menyatakan insentif berpengaruh terhadap kinerja. Hipotesis ini diuji mengunakan uji F. Pengujian hipotesis menggunakan uji $\mathrm{F}$ dilakukan dengan membandingkan antara $\mathrm{F}$ hitung dengan $\mathrm{F}$ tabel. Nilai $\mathrm{F}$ tabel diketahui dengan cara mencarari derajat kebebasan (degree of freedom). Nilai $\mathrm{F}$ tabel didapatkan sebesar 3,21.

Tabel 10. Hasil Uji F Hipotesis Pertama

\begin{tabular}{cccc}
\hline Nilai $\mathrm{F}_{\text {hitung }}$ & Nilai $\mathrm{F}_{\text {tabel }}$ & Sig. & Keterangan \\
\hline 46,619 & 3,21 & 0,000 & Ha Diterima \\
\hline
\end{tabular}

Hasil ini menunjukkan $\mathrm{F}_{\text {hitung }}>$ $\mathrm{F}_{\text {tabel }}(46,619>3,21)$ dengan nilai signifikansi lebih kecil dari 5\% taraf nyata dengan tingkat kepercayaan $95 \% \quad(0,000<0,05)$, yang berarti menerima hipotesis alternatif (Ha) yang diajukan yaitu insentif berpengaruh terhadap kinerja agen marketing assosiacte PT. Jiwasraya Kantor Cabang Malang Kota.

Hipotesis 2 menyatakan motivasi memoderasi pengaruh insentif terhadap kinerja. Uji moderasi dilakukan dengan membandingkan nilai $\mathrm{R}$ square pada analisis regresi linier sederhana dan analisis regresi moderasi. Hasil pengujian regresi linier sederhana mempunyai nilai $\mathrm{R}$ square sebesar
$50,9 \%$ dan $\mathrm{R}$ square dari uji regresi moderasi adalah 70,7 \%. Hipotesis pada penelitian ini diterima ketika nilai $\mathrm{R}$ square pada uji moderasi lebih besar dari nilai $\mathrm{R}$ square pada uji regersi sederhana.

Berdasarkan hasil tersebut, dapat dijelaskan bahwa nilai $\mathrm{R}$ square regresi moderasi lebih besar dari nilai $\mathrm{R}$ square regresi linier sederhana $\quad(50,9 \%>70,7 \%)$. Akibatnya, terjadi penolakan $\mathrm{H} 0$ yang berarti variabel motivasi memoderasi pengaruh variabel insentif terhadap variabel kinerja karyawan di PT. Jiwasraya Kantor Cabang Malang Kota.

Insentif dalam penelitian ini menggunakan teori Sarwoto (2000) 
yang membagi insentif menjadi 2 golongan yaitu insentif materiil dan non materiil. Insentif yang diteliti adalah insentif materiil dalam bentuk uang yang diberikan oleh PT. Jiwasraya Kantor Cabang Malang Kota kepada agen marketing assosiate. Pemberian insentifnya yaitu komisi, bonus wisata dan persistensi polis.

Hasil dari analisis jawaban responden yang diperoleh melalui penyebaran kuisioner kepada 47 responden menunjukkan program insentif di PT. Jiwasraya Kantor Cabang Malang Kota baik. Hasil ini berdasarkan analisis rentang skala yang didapatkan hasil secara rata-rata program insentif baik.

Berdasarkan teori kinerja karyawan dari Robbins (2006) menyatakan bahwa kinerja dapat dilihat melalui 3 indikator yaitu kualitas, kuantitas dan ketepatan waktu. Kinerja agen PT. Jiwasraya Kantor Cabang Malang Kota yang diteliti adalah secara kuantitas dan ketepatan waktu. Hasil analisis kinerja agen dalam rentang skala masuk dalam kategori sangat rendah. Hal ini dapat dilihat dari respon jawaban responden di tiap-tiap peryataan kinerja di kuisioner.

Motivasi dalam penelitian ini menggunakan teori Aldefer dalam Munandar (2001) yaitu kebutuhan untuk eksis, keterkaitan dan pertumbuhan. Hasil dari analisis jawaban responden yang diperoleh melalui penyebaran kuisioner kepada 47 responden menunjukkan tingkat motivasi di PT. Jiwasraya Kantor Cabang Malang Kota adalah rendah. Hal ini dapat dilihat dari respon jawaban responden di tiap-tiap peryataan motivasi di kuisioner.
Hasil uji $F$ dalam pengujian regresi linier sederhana diketahui $\mathrm{F}$ hitung $>\mathrm{F}_{\text {tabel }}(46,619>3,21)$ dengan nilai signifikansi lebih kecil dari $5 \%$ taraf nyata dengan tingkat kepercayaan $95 \%(0,000<0,05)$ yang berarti bahwa insentif berpengaruh terhadap kinerja karyawan PT. Jiwasraya Kantor Cabang Malang Kota. Nilai koefisien regresi yang dihasilkan dalam pengujian ini adalah positif. Hubungan positif ini mengungkapkan semakin baik program insentif yang diberikan oleh PT. Jiwasraya Kantor Cabang Malang Kota maka kinerja karyawan juga akan semakin baik.

Hasil ini serupa dengan penelitian Ananda Bounita, dkk (2013) yang menyatakan insentif mempunyai pengaruh positif terhadap kinerja karyawan PT. Nasmoco Gombel. Hal ini juga diperkuat oleh Handoko (2002) insentif adalah perangsang yang ditawarkan kepada para karyawan untuk melaksanakan kerja sesuai atau lebih tinggi dari standar - standar yang telah ditetapkan.

Hasil MRA menunjukkan bahwa motivasi memoderasi pengaruh insentif terhadap kinerja karyawan. Hipotesis pertama dalam analisis regresi linier sederhana menunjukkan presentase nilai $\mathrm{R}^{2}$ sebesar $50,9 \%$ dan $\mathrm{R}^{2}$ dari uji regresi moderasi adalah 70,7 \%. Hipotesis pada penelitian ini diterima ketika nilai $\mathrm{R}^{2}$ pada uji moderasi lebih besar dari nilai $\mathrm{R}^{2}$ pada uji regersi sederhana $(70,7 \%>50,9 \%)$. Hal ini berarti motivasi memoderasi pengaruh insentif terhadap kinerja karyawan di PT. Jiwasraya Kantor Cabang Malang Kota. Variabel moderasi meningkatkan presentase pengaruh 
insentif dan kinerja karyawan sebesar $19,8 \%$ yang berarti motivasi memperkuat pengaruh insentif terhadap kinerja karyawan. Artinya jika insentif semakin baik dan disertai tingkat motivasi yang tinggi maka kinerja karyawan PT. Jiwasraya Kantor Cabang Malang Kota akan semakin tinggi.

Hasil penelitian ini didukung dengan hasil penelitian dan pendapat para ahli. Penelitian Hari Yogi (2013) yang menyatakan insentif berpengaruh signifikan terhadap motivasi, insentif juga berpengaruh signifikan terhadap kinerja dan motivasi kerja berpengaruh positif terhadap kinerja.

Menurut Mangkunegara (2009) yang mengemukakan Insentif adalah suatu penghargaan yang diberikan kepada karyawan dalam bentuk upah agar mereka bekerja dengan motivasi yang tinggi dan berprestasi dalam tujuan-tujuan organisasi.

\section{SIMPULAN}

Hasil penelitian tentang pengaruh insentif terhadap kinerja karyawan dengan motivasi sebagai variabel motivasi (studi pada agen PT. Jiwasraya (persero) Kantor Cabang Malang Kota) dapat disimpulkan sebagai berikut : (1) Insentif, kinerja dan motivasi disimpulkan sebagai berikut : (a) Insentif yang berupa komisi, bonus wisata dan persistensi polis berjalan dengan baik. (b) Kinerja karyawan sangat rendah dalam mencapai target premi dan polis secara kuantitas dan ketepatan waktu. (c) Motivasi agen rendah berkaitan dorongan mengenai kebutuhan agen akan eksistensi, menjalin hubungan dan berkembang. (2) Insentif berpengaruh positif terhadap kinerja yang berarti jika insentif semakin baik maka kinerja akan semakin tinggi. (3) Motivasi memoderasi pengaruh insentif terhadap kinerja yang berarti apabila insentif semakin baik disertai motivasi yang semakin tinggi maka kinerja akan semakin tinggi.

Saran yang diberikan dalam penelitian ini, sebagai berikut: (1) Bagi Perusahaan: (a) Perusahaan sebaiknya tidak menaikkan persyaratan untuk bonus wisata namun menambah imbalan bonus wisatanya. (b) Perusahaan diharapkan untuk lebih sering berdiskusi dengan agen mengenai target kinerja yang harus dicapai agen secara kuantitas dan ketepatan waktu, sekaligus mendisukusikan kendala agen ketika bekerja. (c) Perusahaan diharapkan dapat meningkatkan motivasi agen dengan tiga cara. Pertama, perusahaan agar sebaiknya meningkatkan kesesuaian antara pendapatan agen dengan pekerjaannya dengan memberikan imbalan tambahan. Kedua, perusahaan sebaiknya selalu memperhatikan, menjaga dan menjamin kebutuhan agen mengenai rasa aman dan nyaman di tempatnya bekerja. Ketiga, perusahaan sebaiknya menambah jadwal pertemuan rutin dengan tujuan meningkatkan interaksi. (2) Bagi peneliti selanjutnya disarankan mengunakan variabel lain yang berpengaruh terhadap kinerja seperti gaya kepemimpinan, lingkungan kerja dan budaya organisasi.

\section{DAFTAR PUSTAKA}

Alamsyah, Firman. 2013. "Pengaruh $\begin{array}{lll}\text { Insentif } & \text { Terhadap Kinerja } \\ \text { Karyawan } & \text { Di Coal Mining }\end{array}$ 
Departement PT. Kalim Prima Coal Sangatta-Kutai Timur". Jurnal di publikasikan (http://ejurnal.untagsmd.ac.id). diakses 30 oktober 2017.

Arikunto, Suharsimi. 2010. Metodologi Penelitian. Penerbit PT. Rineka Cipta: Jakarta.

A.S. Munandar. 2001. Psikologi Industri dan Organisasi. Penerbit Universitas Indonesia: Depok.

Firmandani, Nurai. 2014. "Pengaruh kompensasi terhadap kinerja dengan motivasi kerja sebagai variable moderasi pada bank syariah mandiri kantor cabang yogjakarta". Skripsi dipublikasikan

(eprints.uny.ac.id). diakses 2 November 2017

Ghozali, Imam. 2002. Aplikasi Analisis dengan Program SPSS. Badan Penerbit Universitas Diponegoro: Semarang.

Handoko, T. Hani. 2010. Manajemen Personalia dan Sumber Daya Manusia (edisi 2). BPFE:Yogyakarta.

Hasibuan, Malayu S.P. 2011. Manajemen Sumber Daya
Manusia. Bumi Aksara: Jakarta. Mangkunegara, Anwar Prabu. 2010. Manajemen Sumber Daya Manusia Perusahaan. Cetakan pertama. Penerbit Remaja Rosdakarya: Bandung.

Pasolong, Harbani. 2010. Teori Administrasi Publik. Alfabeta: Bandung.

Ranupandojo, H. dan Suad Husnan. 2002. Manajemen Personalia. Yogyakarta: BPFE.

Robbins, Stephen P. dan Timothy A. Judge. 2016. Perilaku Organisasi Edisi ke-12. Jakarta: Salemba Empat.

Samsudin, Sadili. 2006. Manajemen Sumber Daya Manusia. Cetakan ke-1. CV Pustaka Setia: Bandung.

Sarwoto. 2000. Dasar-dasar Organisasi dan Manajemen. Ghalia Indonesia: Jakarta.

Umar, Husein. 2010. Desain Penelitian MSDM dan Perilaku Karyawan. Rajawali Pers: Jakarta.

Wibowo. 2010. Manajemen Kinerja. PT. Raja Grafindo Parsada: Jakarta. 